\title{
Uitdagingen voor de toekomst van de (groene) criminologie
}

Dr. Lieselot Bisschop

Bisschop, L. (2016). Uitdagingen voor de toekomst van de (groene) criminologie. Tijdschrift voor Criminologie, 58(3), 87-98. doi:10.5553/TvC/0165182X2016058003006

Deze kroniek heeft de bedoeling om een aantal uitdagingen voor de toekomst van de (groene) criminologie scherp te stellen. Achtereenvolgens wordt stilgestaan bij wat de drie traditionele criminologische onderzoeksvragen naar criminalisering, etiologie en sociale reactie betekenen in een 'groene' context. We bespreken daarbij telkens op welke manier de groene criminologie en mainstreamcriminologie elkaar ontmoeten en hebben ook aandacht voor onderzoek in de Lage Landen. Dit laat ons toe om de volgende uitdagingen voor de toekomst van de (groene) criminologie te identificeren: theoretische inbedding, methodologische creativiteit, interdisciplinaire samenwerking en een kijk op milieuschade die verder rijkt dan 'the Global North'.

\section{Inleiding}

In de exacte wetenschappen staat het leefmilieu al sinds de jaren zestig op de onderzoekagenda gezien de maatschappelijke relevantie en urgentie. Sociale wetenschappen daarentegen hebben milieu lange tijd genegeerd. Binnen de criminologie kwam het de voorbije twintig jaar op de agenda van de zogenaamde 'groene criminologie' (Lynch, 1990; South, 1998a). Die focust op milieucriminaliteit gedragingen die strafbaar zijn gesteld (bijv. illegale houtkap, smokkel in gevaarlijk afval en stroperij) - en milieuschade - gedragingen die niet in de strafwet liggen vervat (bijv. vervuiling en biopiraterij). Groene criminologie bestudeert hoe milieuwetgeving en -regulering zich ontwikkelen en worden geïmplementeerd. Milieucriminaliteit en -schade blijven echter ook vandaag nog voor een stuk een criminologische blinde vlek (South \& Brisman, 2013). Daar zijn verschillende redenen voor.

Ten eerste staat de traditionele criminologische focus op de zogenaamde 'nuts, sluts and perverts' in schril contrast met de diversiteit en complexiteit van oorzaken, verantwoordelijken en oplossingen inzake milieuschade en -criminaliteit (Halsey \& White, 1998). Slachtoffers noch daders zijn eenduidig te benoemen. De schade van illegale afvaltransporten zit in de vervuiling van grond, water en lucht, meteen zichtbaar in een vervuilde rivier of over enkele jaren wanneer een buurtbewoner kanker ontwikkelt. Schade zit eveneens in het verlies aan kostbare secundaire grondstoffen en in concurrentievervalsing voor de legale afvalmarkt (Bisschop, 2012). Afvalsmokkelaars hebben een directe verantwoordelijkheid, maar producenten en consumenten zijn indirect betrokken en ook het gebrekkige optreden van overheden speelt een rol. Alle gevolgen en verantwoordelijkheden ontsluieren vereist criminologische verbeelding. 
Ten tweede betekent criminologisch onderzoek vaak vooral een retrospectieve beschrijving en analyse van criminaliteitsfenomenen met de bedoeling om een bepaald gedrag te criminaliseren, begrijpen, bestraffen en/of behandelen (Shearing, 2015). Dat werkt goed voor veel types criminaliteit en zelfs voor diverse vormen van milieucriminaliteit, maar een deel van het verhaal ontbreekt. Milieucriminaliteit vereist immers prospectie en proactiviteit inzake schadelijke gevolgen op lange termijn, die we ons nu amper kunnen inbeelden, het welzijn van toekomstige generaties in gedachten houdend (Potter, 2012). Bij afval vereist het bijvoorbeeld dat we nadenken over de mogelijke schadelijke gevolgen bij het in onbruik raken van technologie die morgen pas wordt ontwikkeld.

Een derde reden ligt in de zoektocht naar het optimale preventie- en controlemechanisme. De preventie van en controle op milieucriminaliteit staan lang niet gelijk aan de traditionele controlemechanismen in de strafrechtsketen en zelfs niet bij uitbreiding die van het bestuursrecht. Een oplossing voor de schade door illegale afvaltransporten vereist bijvoorbeeld een blik op de gehele toeleveringsketen (Van Erp \& Huisman, 2010). Hoewel criminologie vertrouwd is met een brede kijk op oplossingen voor criminaliteit, zoals bijvoorbeeld in herstelrecht of responsieve regulering (Aertsen e.a., 2010; Braithwaite, 2008), plooien we graag terug op het strafrecht om oplossingen slagkracht te geven.

De redenen die hierboven zijn aangehaald, kunnen nog uitgebreid worden en zijn niet met alle nodige nuance toegelicht. Ze zijn bedoeld als aanzet voor een discussie over wat milieucriminaliteit voor de meer 'traditionele' criminologie kan betekenen en over wat groene criminologie van de 'mainstream' criminologie kan leren. Deze kroniek probeert een aantal uitdagingen voor de toekomst van de (groene) criminologie scherp te stellen door achtereenvolgens stil te staan bij wat de drie traditionele criminologische onderzoeksvragen naar criminalisering, etiologie en sociale reactie betekenen in een 'groene' context.

\section{Definitie van criminaliteit en schade}

Groene criminologie wil onderzoeken, verhelderen en analyseren hoe het ontstaan van, de controle op en de weerstand tegen schade aan milieu, ecosystemen, planten en dieren vorm krijgen (Brisman \& South, 2013). Daarbij wordt aandacht besteed aan verklaringen op individueel en groepsniveau en binnen zowel socio-economische als politieke context (White \& Heckenberg, 2014). Dit past binnen de bredere kritisch criminologische traditie om verder te kijken dan dat wat expliciet is gecriminaliseerd of zelfs gereguleerd en om de gedragingen van de machtigen tegen het licht te houden. Sutherland (1945) met witteboordencriminaliteit, Chambliss (1978) met state-organized crime en Hillyard en Tombs (2007) met social harm zijn daarbij enkele van de lichtende voorbeelden. Kritische criminologie beklemtoont al lang hoe belangrijk het is om aandacht te hebben voor activiteiten die schadelijk zijn, maar niet strafbaar of gereguleerd (Barak, 2015; McBarnett, 1983; Passas \& Goodwin, 2004). 
Het concept 'schade' (social harm) omvat de diversiteit aan gedragingen en nalatigheden die gepaard gaan met het misbruik, gebruik en slecht management van milieu en natuurlijke rijkdommen, inclusief de klimaatverandering, vervuiling en dierenrechten (Heckenberg, 2008). Het onderscheid tussen strafrechtelijke, burgerrechtelijke of bestuursrechtelijke overtredingen is daarbij een sociale constructie ingegeven door de belangen van de kapitaalkrachtigen of politiekvaardigen en geen indicatie voor de omvang of ernst van de schade (Lynch \& Stretesky, 2003). De diversiteit en complexiteit aan schadelijke gedragingen en nalatigheden inzake milieu zijn dan ook niet altijd makkelijk met de criminologische traditie(s) te verzoenen (Lynch, 2013). Zeker omdat de interpretatie van schadelijkheid kan verschillen naargelang wie het probleem definieert en waar dit plaatsvindt (White, 2011). In veel (Angelsaksische) landen worden overtredingen van reguleringswetgeving bijvoorbeeld niet als criminaliteit beschouwd. Schade aan het milieu wordt aanvaard als onvermijdelijk in functie van economische vooruitgang (Stretesky e.a., 2013). Denk bijvoorbeeld aan het geven van licenties voor bedrijven zolang hun emissies (vervuiling dus) onder een bepaalde grens blijven. Dat maakt het milieu-'criminele' aspect eerder iets administratiefs: we reguleren het zodat het probleem gemanaged wordt (Flannery \& May, 2000). Verschillende internationale milieuconventies, zoals de Basel Conventie over gevaarlijk afval en de CITES conventie over bedreigde dier- en plantensoorten, zijn op deze leest geschoeid en reguleren handel eerder dan ze milieuschade criminaliseren.

Groen criminologisch onderzoek bestudeert diverse mogelijke slachtoffers en verantwoordelijken voor milieuschade, inclusief activiteiten die in de meeste situaties perfect legaal zijn, zoals boskap of visvangst, maar die in bepaalde omstandigheden als milieucriminaliteit worden gedefinieerd (Cardwell e.a., 2011). Op die manier wordt er rekening mee gehouden dat industriële activiteiten (bijv. agroindustrie en gaswinning), hoewel niet noodzakelijk intrinsiek crimineel, mogelijk bijdragen aan het verarmen of uitbuiten van natuurlijke rijkdommen. Dit bouwt op een mensenrechtendefinitie van criminaliteit (Schwendinger \& Schwendinger, 1975) omdat de ongelijke verdeling van de schade tussen bevolkingsgroepen en potentiële langetermijneffecten in rekening worden gebracht (Mohai \& Saha, 2007; White, 2011). Daarenboven neemt het de rechten van dieren, planten en ecosystemen als directe en indirecte slachtoffers van milieucriminaliteit in overweging (Beirne \& South, 2007; Halsey $\&$ White, 1998). Deze kijk op sociale en ecologische schade laat het toe aandacht te besteden aan de externalisering van schade. Dit beperken tot de eigen landsgrenzen schiet onverwijld tekort. Een lokale case kan globaal effect hebben en het lokale effect is onmogelijk te vatten zonder de bredere sociale, economische en politieke context. Niettemin schiet zelfs een focus op schade mogelijk tekort in het bevatten van een complex samenlevingsprobleem. Sommige handelsstromen in milieugoederen hebben, naast de negatieve, ook positieve gevolgen (Bisschop, 2015).

Sommigen zullen zich ongetwijfeld de vraag stellen of een dergelijke brede definitie ons niet te ver brengt van de kern van de criminologie. Het leidt in ieder geval tot een verbreding van de focus: van straatcriminaliteit via bedrijfscriminaliteit en georganiseerde criminaliteit naar staatscriminaliteit en nu 
criminaliteit tegen dieren, planten of ecosystemen. Naar mijn mening is die verbreding terecht in een wereld waarin de milieuproblematiek - en de bijdrage van de mens eraan - ontegensprekelijk is. Bovendien staat milieu steeds centraler op de beleidsagenda en zelfs op de veiligheidsagenda. Voor deze evolutie kan een traditioneel beleidsgerichte wetenschap als criminologie moeilijk ongevoelig blijven. Wel is een aantal kritische kanttekeningen te maken, zoals over het belang van wetenschappelijk genoeg te blijven en de grens met puur activisme te bewaken. Daar gaan we later in deze kroniek uitgebreider op in.

\section{Oorzaken en verantwoordelijken}

Een groene criminologische kijk op oorzaken en verantwoordelijkheden heeft diverse raakvlakken met meer traditionele of al langer bestaande concepten binnen de criminologie, zoals georganiseerde misdaad, bedrijfscriminaliteit en gouvernementele (of staats)criminaliteit. Ook in de Lage Landen wordt hier al geruime tijd aandacht aan besteed, vaak vanuit een bredere theoretische invalshoek, maar met relevantie voor milieu. De sterkte van een groene kijk op milieucriminaliteit en -schade ligt precies bij de aandacht voor diverse mogelijke oorzaken, daders en verantwoordelijken.

Voor sommige milieudelicten is het meteen mogelijk om de dader te benoemen, maar meestal is er meer complexiteit mee gemoeid. Een deel van de milieudelicten heeft bedrijven als directe verantwoordelijken, zoals wanneer afvalwater wordt geloosd zonder de schadelijke stoffen te verwijderen (Van Wingerde, 2015). Het gaat echter vaker om indirect daderschap of om fouten met milieuschade als gevolg, waarbij causaliteit moeilijk te bewijzen is. Het hardmaken van de intentie om te schaden (mens rea) is daarbij nog problematischer, zeker bij routineuze bedrijfsactiviteiten of wanneer bedrijven hun verantwoordelijkheid proberen te ontkennen of verbloemen (Oreskes \& Conway, 2010). Ook georganiseerde criminaliteit heeft een aandeel in milieucriminaliteit, zij het moeilijk te kwantificeren (Albrecht, 2004; Europol, 2011). De rol van de georganiseerde misdaad in de afvalsector is in Italië en de Verenigde Staten reeds lang gekend (Massari \& Monzini, 2004; Rebovich, 1992) en ook de handel in ivoor en andere bedreigde dieren en planten ligt (gedeeltelijk) in hun handen (Bennett, 2015; Van Uhm, 2016). Criminele groepen worden bovendien geholpen door corrupte overheidsambtenaren, die in theorie milieuregulering implementeren, maar in praktijk een oogje dichtknijpen voor illegale handel en valse certificaten toekennen (UNODC, 2012). De connectie naar overheden als medeverantwoordelijken voor milieuschade en -criminaliteit door het niet of te weinig reguleren of door het niet of laks implementeren van milieuwetgeving is dan niet meer veraf (South, 1998b).

Naast bedrijven, overheden en georganiseerde misdaad ligt de verantwoordelijkheid voor milieuschade in systemische processen. Dit is binnen de groene criminologie onder meer in de theorie van de 'treadmill of production' geconcretiseerd (Stretesky e.a., 2013). Dit vraagt aandacht voor werkelijke milieukosten van productie- en consumptieprocessen en voor de dynamieken van externalisering 
tussen 'the Global North' en 'the Global South' Het omvat een analyse van de economische, sociale en politieke context (bijv. het politiek-economisch systeem) waarin of waardoor milieuschade optreedt. Binnen het kapitalisme wordt bijvoorbeeld aanvaard dat productieprocessen in afval resulteren. Het wordt gereguleerd door er een prijs op te plakken, bijvoorbeeld een belasting op de uitstoot van $\mathrm{CO}_{2}$. Illegaliteit treedt op wanneer het andere stoffen zijn dan in de rapportering vermeld of wanneer het om het bewust ongemerkt lozen van afval gaat. Binnen dit 'systeem' kleven we ook vaak onterecht - het label 'ongeluk' op milieuschade, zelfs wanneer de onvoorziene omstandigheden eigenlijk te voorzien waren (bijv. de nucleaire ramp in Fukushima: Levi \& Horlick-Jones, 2013). Bij de systemische oorzaken van milieuschade hoort ook de ongebreidelde consumptie en dus iedere individuele consument. Wanneer iedereen een beetje verantwoordelijk is, maar niemand zich echt verantwoordelijk voelt, komt de 'tragedy of the commons' om het hoekje kijken (Hardin, 1968).

De verantwoordelijkheid voor milieucriminaliteit gaat veel verder dan individuele daders en vereist een analyse op aggregaat niveau. Vaak is het individuele gedrag niet schadelijk, maar wordt het problematisch wanneer iedereen het stelt. Milieuschade is dus een routineus gevolg van dagdagelijkse sociale en economische patronen, ongeacht of ze gecriminaliseerd zijn (Shearing, 2015). Dit is overigens parallel aan ontwikkelingen in de meer traditionele criminologie, want ook daar wordt aandacht besteed aan criminaliteit of schade als gevolg van routines in de samenleving. Wanneer de vraag naar routines of opeengestapelde schade (harm by accumulation) wordt gesteld, komen we onvermijdelijk bij voormelde productie- en consumptiepatronen in de huidige samenleving terecht.

De verantwoordelijken voor milieucriminaliteit benoemen past niet binnen een traditioneel daderslachtofferpatroon (Hall, 2013). We onderscheiden algemene systemische oorzaken van milieuschade en specifieke omstandigheden van schade of risico waarbij de verantwoordelijkheid bij personen of organisaties ligt (White, 2011). Dit laatste betekent nog niet noodzakelijk dat ze ook als daders zullen worden behandeld door regulerende instanties. Het gaat immers niet noodzakelijk om het doelbewust schaden van het leefmilieu. Vaak is er een veel bredere dynamiek van onzorgvuldigheid of nalatigheid. Een etiologische analyse vraagt bovendien om de rol van overheden en bedrijven in het definiëren, faciliteren, plegen of neutraliseren van milieucriminaliteit mee in overweging te nemen. De verantwoordelijke benoemen is vaak controversieel, zeker wanneer er tegengestelde ecologische en economische belangen spelen.

\section{Sociale reactie}

Een groene criminologische bril laat ons niet alleen toe om kritisch over criminalisering of etiologie van milieuschade na te denken, maar daagt onderzoekers ook uit om mogelijke oplossingen te bestuderen, evalueren en bedenken. Milieucriminaliteit is, zoals eerder aangegeven, vaak erg complex in haar oorzaken, met elementen op individueel, organisatorisch en samenlevingsniveau. Het is dan ook logisch dat de sociale reactie met deze complexiteit rekening houdt. Milieuschade en -criminaliteit 
vereisen dat onderzoekers en beleidsmakers nadenken over een aanpak voor concrete actuele milieuschade en tegelijk rekening houden met gevolgen op de langere termijn. Die concrete milieuschade verwijst bijvoorbeeld naar de smokkel van bedreigde dieren en planten of van gevaarlijk afval. Het uitweiden over elk van deze fenomenen zou ons te ver leiden, maar kort gezegd kunnen we stellen dat het controle en preventie-inspanningen vereist in landen van oorsprong, transit en bestemming van gesmokkelde goederen, waardoor op korte termijn op bepaalde types milieucriminaliteit kan worden ingegrepen. Het aanpakken van de milieuschade op langere termijn is veel moeilijker omdat systemische oorzaken er deel van zijn. Dit vereist dat de vinger aan de pols wordt gehouden over onverwachte langetermijngevolgen van milieuschade. Verschillende sociale wetenschappers pleiten daarom voor de erkenning van ecocide als vijfde misdrijf tegen de mensheid (Higgins e.a., 2013). Dit maakt groene criminologie onvermijdelijk sociaal geëngageerd en vaak ook actie- en oplossingsgericht (Higginbottom, 2008).

Milieucriminaliteit is als fenomeen, ondanks groeiende aandacht in de laatste jaren, nog steeds relatief onbekend. Het is een fenomeen aan de buitengrenzen van criminaliteit en aan de buitengrenzen van waar criminologen zich mee bezighouden. Dat maakt het een des te interessanter thema om over preventie en controle te leren. Het laat ons toe om anders over veiligheid en sociale problemen na te denken, door een brede lens die niet tot strafrechtelijke definities en reacties is beperkt, en door kritisch te beschouwen hoe criminalisering, etiologie en de sociale reactie enerzijds en de opgelopen schade anderzijds niet noodzakelijk parallel lopen. Het vraagt ook dat we nadenken over de mogelijke rol in controle en preventie van andere actoren (bedrijven, ngo's) dan de traditionele overheidsinstanties in het veiligheidsdispositief en over controle en preventie op diverse niveaus van de samenleving binnen een globale en geglobaliseerde context. Criminologie kan daarvoor inspiratie opdoen bij bestuurskunde, organisatiewetenschappen en ecologie. Door op de interacties tussen overheden, bedrijven, gemeenschappen en ngo's te focussen kunnen we de relevantie van elk van deze actoren voor de aanpak en preventie van milieucriminaliteit evalueren (Bernstein \& Cashore, 2007). Een traditionele kijk op sociale controle met louter een rol voor het strafrechtsproces is immers te eng om antwoord te bieden op milieucriminaliteit (Du Rées, 2001). Bovendien moeten we in gedachten houden dat een groot deel van milieucriminaliteit fraude met regulering betreft ('regulatory crimes'), wat eigenlijk een pervers gevolg is van de milieuwetgeving. Ook het marktsysteem kan (milieu)criminogeen zijn, waardoor bij het zoeken van oplossingen in de marktcompetitie kritische zin aan de dag gelegd moet worden (Shearing, 2015).

De vraag welke actor (politie, justitie, milieuadministraties, overheden, bedrijven, ngo's of burgers) of welke samenwerking tussen actoren het best in staat is om de milieuproblematiek aan te pakken, is onderwerp van onderzoek binnen een diversiteit aan sociale wetenschappen. Het is daarom ook essentieel dat groene criminologen multidisciplinair onderzoek (blijven) opzetten met andere sociale wetenschappen, zoals veiligheidsstudies, en met exacte wetenschappen, zoals biologie, toxicologie of chemie. Tegelijk moeten we daarbij kritisch blijven over de rol en effectiviteit van dergelijke hybride 
controle- en preventieraamwerken, over de interacties tussen actoren binnen dat raamwerk en over de veranderende rol van de overheid. Theoretische modellen zijn immers niet altijd makkelijk toepasbaar noch realistisch in de complexe maatschappelijke context waarin sociale reacties plaatsvinden.

\section{Uitdagingen voor de toekomst van de (groene) criminologie}

\section{Theorievorming}

Groene criminologie is geen theorie op zich en ambieert dat ook niet, maar wordt wel eens - vaak terecht - verweten te weinig theoretisch te zijn. Op die manier dreigt zij misschien wel onderschat en misbegrepen te worden, want de oorsprong ligt in een kritische blik op hoe kapitalisme ecosystemen kan verstoren en schaden (Lynch, 1990), vandaag verdergezet in voormelde 'treadmill of production'theorie (Stretesky e.a., 2013). Groene criminologie is meermaals de uitdaging aangegaan om iets meer naar theorievorming toe werken (bijv. Ruggiero \& South, 2013; White, 2013). Ook meer klassieke criminologen bestuderen milieucriminaliteit en passen er meer traditionele theorieën, zoals situationele-criminaliteitspreventie (Lemieux, 2014; Petrossian \& Clarke, 2013) en straintheorie (Agnew, 2012) op toe. Ook binnen veiligheidsstudies staat milieu op de agenda (Shearing, 2015). Daarnaast zijn de theorieën over transnationale of georganiseerde criminaliteit en evenzeer deze over bedrijfscriminaliteit een meerwaarde om milieucriminaliteit te doorgronden (bijv. legal-illegal interfaces of criminogene asymmetrieën; Passas, 2003).

Gezien de diversiteit aan bijdragende elementen en (mede)verantwoordelijken hoeft het weinig te verbazen dat geen enkele theorie alle milieuschade kan verklaren, net zoals er geen enkele theorie is die alle criminaliteit kan verklaren. In tegenstelling tot de mainstreamcriminologie zijn er echter weinig pogingen gedaan tot een meer alomvattende theorie betreffende milieucriminaliteit. Op zich is dat niet zo verwonderlijk aangezien groene criminologie rust op diverse bouwstenen binnen criminologie, sociologie, bestuurskunde, toxicologie, ecologie, enz. en deze dus moeilijk onder één noemer zijn te ondervangen. Tegelijk is deze theoretische inbedding misschien wel een van de grootste uitdagingen van de groene criminologie. Het is aan groene criminologen om uitdrukkelijker de verbinding te maken met bestaande theoretische raamwerken in de criminologie en andere disciplines en de meerwaarde van een groene criminologische kijk op de samenleving aan te tonen. Het is ook aan de andere criminologen om open te staan voor een groene kijk op criminaliteit, zowel in de enge zin, verwijzend naar het bestuderen van allerhande types milieucriminaliteit, als in de brede zin van het mogelijke effect van milieuproblemen op traditionele criminaliteitsfenomenen.

\section{Methodologische creativiteit}

Traditionele theorieën op milieucriminaliteit toepassen vereist creativiteit om met de methodologische uitdagingen om te gaan, wat meteen de tweede uitdaging vormt. Groene criminologie wordt wel eens verweten te weinig op empirie gebaseerd te zijn. Studies in de laatste twee decennia hebben dat 
ondertussen gedeeltelijk goedgemaakt, hoewel ze zich vaak tot nationaal specifieke cases beperken. Veel onderzoek naar milieucriminaliteit berust op erg lokaal ingestoken cases, waardoor het verzamelen en systematisch vergelijken van empirisch materiaal niet evident is. Er is bijvoorbeeld zelden veel politionele informatie beschikbaar omdat er weinig grote opsporingsonderzoeken over worden gevoerd, hoewel dat per land erg verschilt (EnviCrimeNet, 2014; Eurojust, 2014). Bovendien vindt veel milieucriminaliteit plaats in landen waar de rechtsstaat relatief zwak is en er dus amper officiële statistieken te vinden zijn. Milieucriminaliteit en -schade zijn echter steeds meer een aanvaard onderwerp voor criminologisch onderzoek, ook in de Lage Landen. ${ }^{1} \mathrm{Er}$ is een rijkdom aan studies over (de regulering van) criminaliteit en schade gerelateerd aan afval en vervuiling (bijv. Kluin, 2014; Van Erp \& Huisman, 2010; Van Wingerde, 2012) en studies over schade en criminaliteit gerelateerd aan (bedreigde) dieren en planten (bijv. Boekhout van Solinge, 2014; Cazaux, 1998; Van Uhm, 2016).

Het blijft natuurlijk wel gedeeltelijk een studie over thema's die niet meteen aan de oppervlakte drijven en vaak zelfs bewust verborgen worden gehouden door de verantwoordelijken ervoor. Het vereist dus enige creativiteit inzake onderzoeksdesign. Binnen groene criminologie past een diversiteit aan methodes en methodologische tradities. Net zoals bij ander onderzoek hangt dit af van de doelstellingen en de opzet van het onderzoek. Diverse studies gebruiken kwantitatieve technieken om milieuschade te bestuderen (bijv. Stretesky \& Lynch, 1998) en ander onderzoek koos voor de rijkdom van kwalitatief onderzoek (bijv. Mol, 2013). Vaak vereist het echter dat we tussen diverse niveaus van analyse navigeren met een complexe onderzoeksopzet als resultaat. Het is dan zaak om transparant te zijn over methodologische keuzes en in debat te gaan met diegenen die je aanpak bekritiseren.

\section{Westerse en antropocentrische bril}

Een derde uitdaging is het vermijden van een louter westerse onderzoekagenda over de impact en oorzaken van en mogelijke oplossingen voor milieucriminaliteit en -schade. Ook al zijn veel onderzoeken van erg hoge kwaliteit wanneer ze door 'the Global North' over 'the Global South' worden uitgevoerd, toch is het essentieel om het perspectief van de ander, in dit geval de meer direct betrokkene, mee te nemen (Friedrichs \& Rothe, 2014). Net zoals er vroeger amper iets over witteboordencriminaliteit buiten de Angelsaksische context door niet-Angelsaksische onderzoekers was bestudeerd (Van Erp e.a., 2015), is dat vandaag door de band genomen het geval voor milieucriminaliteit. Vaak zijn de milieuproblemen bovendien als ongeval of ramp benoemd en zijn ze niet gekend buiten de grenzen van het eigen land. Met de sociale media en communicatiemogelijkheden van vandaag is dat al verbeterd, maar wetenschappers zouden er meer op kunnen inzetten.

Een focus op milieuschade in alle vormen vraagt ook dat we afstappen van een vooringenomenheid met schade aan de mens, een focus die eigen is aan veel criminologisch onderzoek en waar ook groene

\footnotetext{
${ }^{1}$ Voor een uitgebreid overzicht verwijs ik de lezer naar Bisschop \& Boekhout van Solinge, 2016, 17-40.

Daarnaast is ook recent een Europese studie over milieucriminaliteit afgerond: www.EFFACE.eu.
} 
criminologie zich schuldig aan maakt. Dit vereist natuurlijk in de eerste plaats dat we het bestaan van de milieuproblematiek zoals bijvoorbeeld klimaatverandering erkennen, iets wat in sommige landen tot op vandaag met intensief lobbywerk wordt tegengegaan (Brisman, 2012). De schade aan mensen, dieren, planten en ecosystemen reikt verder dan een antropocentrische of westerse kijk op de wereld en wordt lang niet altijd door iemand gemeld. Ook blijft daarbij natuurlijk de uitdaging van comparatief onderzoek, omdat de definities van milieucriminaliteit erg verschillend zijn.

\section{Interdisciplinair onderzoek en dialoog}

Een vierde uitdaging is het opzetten van interdisciplinair onderzoek en dialoog. Dit betekent in de eerste plaats binnen de criminologie grenzen overbruggen. Groene criminologie is immers niet ondermijnend voor mainstream criminologie, maar juist verbredend. Het is natuurlijk wel verschillend van een positivistische focus op criminaliteit en vraagt dat politieke of socio-economische vragen gesteld kunnen worden, net zoals binnen de kritische criminologie (Van Swaaningen, 1999). Tegelijk is het aan de groene criminologie om de hand te reiken naar onderzoek over milieucriminaliteit vanuit andere theoretische invalshoeken (bijv. crimes of the powerful, bedrijfscriminaliteit, situationelecriminaliteitspreventie, responsieve regulering, enz.). Onderzoek naar milieucriminaliteit is noodzakelijk interdisciplinair, zowel over de grenzen van sociale (criminologie, sociologie, strafrecht, filosofie, psychologie, geografie, economie, veiligheidsstudies) als over die van exacte wetenschappen heen (chemie, biologie, gezondheidswetenschappen, toxicologie). De scheiding tussen de natuurlijke en de sociale wetenschappen is eigenlijk niet bevorderlijk voor het onderzoek over milieucriminaliteit. Het zal ongetwijfeld een herijking vragen om over de grenzen heen samen te werken en de methodologische en theoretische caleidoscoop te verwelkomen.

\section{Literatuur}

Aertsen, I., Vanfraechem, I. \& Crawford, A. (2010). Restorative justice and crime prevention. Presenting a theoretical exploration, an empirical analysis and the policy perspective. Final report of the European project 'Restorative Justice and Crime Prevention'. Rome: Italian Ministry of Justice, Department of Juvenile Justice.

Agnew, R. (2012). Dire forecast: a theoretical model of the impact of climate change on crime. Theoretical Criminology, 16(1), 21-42.

Albrecht, H.-J. (2004). The extent of organized environmental crime. In: F. Comte \& L. Krämer (eds.). Environmental crime in Europe. Rules of sanctions. Groningen: Europe Law Publishing, 71102.

Barak, G. (2015). The Routledge international handbook of the crimes of the powerful. New York: Routledge.

Beirne, P. \& South, N. (2007). Issues in green criminology. Confronting harms against environments, 
humanity and other animals. Portland: Willan.

Bennett, E.L. (2015). Legal ivory trade in a corrupt world and its impact on African elephant populations. Conservation Biology, 29(1), 54-60.

Bernstein, S. \& Cashore, B. (2007). Can non-state global governance be legitimate? An analytical framework. Regulation \& Governance, 1(4), 347-371.

Bisschop, L. (2012). Is it all going to waste? Illegal transports of e-waste in a European trade hub. Crime, Law and Social Change, 58(3), 221-249.

Bisschop, L. (2015). Governance of the illegal trade in e-waste and tropical timber. Case studies on transnational environmental crime. Farnham, UK/Burlington, USA: Ashgate.

Bisschop, L. \& Boekhout van Solinge, T. (2016). Van twijgje tot tak. Een geschiedenis van de groene criminologie. Cahiers Politiestudies, 38.

Boekhout van Solinge, T. (2014). Natural resources and organized crime. In: L. Paoli (ed.). Oxford handbook on organized crime. New York: Oxford University Press, 500-528.

Braithwaite, J. (2008). Regulatory capitalism: how it works, ideas for making it work better. Cheltenham: Edwar Elgar.

Brisman, A. (2012). The cultural silence of climate change contrarianism. In: R. White (ed.). Climate change from a criminological perspective. New York: Springer, 41-70.

Brisman, A. \& South, N. (2013). Conclusion: the planned obsolescence of planet earth? How green criminology can help us learn from experience and contribute to our future. In: N. South \& A. Brisman (eds.). Routledge handbook of green criminology. London/New York: Routledge, 409-417.

Cardwell, P., Hall, M. \& French, D. (2011). Tackling environmental crime in the European Union: the case of the missing victim? Environmental Law and Management, 23(3), 113-121.

Cazaux, G. (1998). Legitimating the entry of the animals issue into (critical) criminology. Humanity \& Society, 22(4), 365-385.

Chambliss, W.J. (1978). On the take: from petty crooks to presidents. Bloomington: Indiana University Press.

EnviCrimeNet (2014). Intelligence project on environmental crime - preliminary report on environmental crime in Europe (Vol. 2014).

Erp, J. van \& Huisman, W. (2010). Smart regulation and enforcement of illegal disposal of electronic waste. Criminology \& Public Policy, 9(3), 579-590.

Erp, J. van, Huisman, W. \& Vande Walle, G. (eds.) (2015). The Routledge handbook of white-collar and corporate crime in Europe. London: Routledge.

Eurojust (2014). Strategic project on environmental crime. The Hague: Eurojust.

Europol (2011). OCTA 2011 - EU organised crime threat assessment. The Hague: European Police Office.

Flannery, B.L. \& May, D.R. (2000). Environmental ethical decision making in the U.S. metal- 
finishing industry. Academy of Management Journal, 43(4), 642-662.

Friedrichs, D. \& Rothe, D. (2014). State-corporate crime and major financial institutions: interrogating an absence. State Crime Journal, 3(2), 146-162.

Hall, M. (2013). Victims of environmental harm: rights, recognition and redress under national and international law. Frontiers of criminal justice. London: Routledge.

Halsey, M. \& White, R. (1998). Crime, ecophilosophy and environmental harm. Theoretical Criminology, 2(3), 345-371.

Hardin, G. (1968). The tragedy of the commons. Science, 162, 1243-1248.

Heckenberg, D. (2008). Studying environmental crime: key words, acronyms and sources of information. In: R. White (ed.). Environmental crime: a reader. Cullompton: Willan Publishing, 9-24.

Higginbottom, A. (2008). Solidarity action research as methodology: the crimes of the powerful in Colombia. Latin American Perspectives, 35(5), 158-170. doi: 10.1177/0094582x08321969.

Higgins, P., Short, D. \& South, N. (2013). Protecting the planet: a proposal for a law of ecocide. Crime, Law and Social Change, 59(3), 251-266.

Hillyard, P. \& Tombs, S. (2007). From 'crime' to social harm? Crime, Law and Social Change, 48, 925.

Kluin, M.H.A. (2014). Optic compliance: enforcement and compliance in the Dutch chemical industry. Delft: TU Delft.

Lemieux, A. (2014). Situational prevention of poaching. Abingdon/New York: Routledge.

Levi, M. \& Horlick-Jones, T. (2013). Interpreting the Fukushima Daiichi nuclear incident: some questions for corporate criminology. Crime, Law and Social Change, 59(5), 487-500.

Lynch, M. (1990). The greening of criminology: a perspective for the 1990s. The Critical Criminologist, 2-3(3-4), 11-12.

Lynch, M. (2013). Reflection on green criminology and its boundaries: comparing environmental and criminal victimization and considering crime from an eco-city perspective. In: N. South \& A. Brisman (eds.). The Routledge international handbook of green criminology. Abingdon/New York: Routledge, 43-57.

Lynch, M. \& Stretesky, P. (2003). The meaning of green: contrasting criminological perspectives. Theoretical Criminology, 7(2), 217-238.

Massari, M. \& Monzini, P. (2004). Dirty businesses in Italy: a case-study of illegal trafficking in hazardous waste. Global Crime, 6(3-4), 285-304.

McBarnett, D. (1983). Victims in the witness box - confronting victimology's stereotype. Contemporary Crises, 7, 279-303.

Mohai, P. \& Saha, R. (2007). Racial inequalities in the distribution of hazardous waste: a nationallevel assessment. Social Problems, 54, 343-370.

Mol, H. (2013). A gift from the tropics to the world: power, harm, and palm oil. In: D. Westerhuis, R. 
Walters \& T. Wyatt (eds.). Emerging issues in green criminology: exploring power, justice and harm. Basingstoke: Palgrave/Macmillan, 242-260.

Oreskes, N. \& Conway, E.M. (2010). Defeating the merchants of doubt. Nature, 465(7299), 686-687.

Passas, N. (2003). Cross-border crime and the interface between legal and illegal actors. Security Journal, 16(1), 19-38.

Passas, N. \& Goodwin, N. (2004). It's legal but it ain't right: harmful social consequences of legal industries. Ann Arbor: University of Michigan Press.

Petrossian, G.A. \& Clarke, R.V. (2013). Explaining and controlling illegal commercial fishing an application of the CRAVED theft model. British Journal of Criminology,54(1), 73-90.

Potter, G. (2012). Pushing the boundaries of (a) green criminology: environmental harm as a cause of crime. The Green Criminology Montly, 3: http://greencriminology.org/2012/11/the-greencriminology-monthly-3-november-2012/.

Rebovich, D.J. (1992). Dangerous ground: the world of hazardous waste crime. New Brunswick, NJ: Transaction Publishers.

Rées, H. du (2001). Can criminal law protect the environment? Journal of Scandinavian Studies in Criminology and Crime Prevention, 2, 109-126.

Ruggiero, V. \& South, N. (2013). Green criminology and crimes of the economy: theory, research and praxis. Critical Criminology, 21, 359-373.

Schwendinger, H. \& Schwendinger, J. (1975). Defenders of order or guardians of human rights? In: I. Taylor, P. Walton \& J. Young (eds.). Critical criminology. London: Routledge, 113-146.

Shearing, C. (2015). Criminology and the anthropocene. Criminology and Criminal Justice, 15(3), 255-269.

South, N. (1998a). A green field for criminology: a proposal for a perspective. Theoretical Criminology, 2(2), 211-233.

South, N. (1998b). Corporate and state crimes against the environment. In: V. Ruggiero, N. South \& I. Taylor (eds.). The new European criminology: crime and social order in Europe. London/New York: Routledge, 443-461.

South, N, \& Brisman, A. (2013). Routledge international handbook of green criminology. Abingdon/New York: Routledge.

Stretesky, P. \& Lynch, M. (1998). Corporate environmental violence and racism. Crime, Law and Social Change, 30(2), 163-184.

Stretesky, P., Long, M. \& Lynch, M. (2013). The treadmill of crime: political economy and green criminology. London/New York: Routledge.

Sutherland, E. (1945). Is 'white collar crime' crime? American Sociological Review, 10(2), 132-139.

Swaaningen, R. van (1999). Reclaiming critical criminology: social justice and the European tradition. Theoretical Criminology, 3(1), 5-28.

Uhm, D. van (2016). De verwevenheid tussen de onder- en bovenwereld in de wildlife handel. Cahiers 
Politiestudies, 38, 41-54.

UNODC (2012). Transnational organised crime assessment: East Asia and the Pacific.

White, R. (2011). Transnational environmental crime. Towards an eco-global criminology. New York: Routledge.

White, R. (2013). Environmental harm: an eco-justice perspective. Bristol: Policy Press.

White, R. \& Heckenberg, D. (2014). Green criminology: an introduction to the study of environmental harm. Abingdon/New York: Routledge.

Wingerde, K. van (2012). De afschrikking voorbij. Een empirische studie naar afschrikking, generale preventie en regelnaleving in de Nederlandse afvalbranche. Erasmus School of Law (ESL).

Wingerde, K. van (2015). The limits of environmental regulation in a globalized economy. In: J. van Erp, W. Huisman \& G. Vande Walle (eds.). The Routledge handbook of white-collar and corporate crime in Europe. London: Routledge, 260. 